\title{
Fenomenologia heideggeriana como referencial para estudos sobre formação em saúde*
}

\author{
Alberto Durán González ${ }^{1}$ \\ Mara Lúcia Garanhani² \\ Maira Sayuri Sakay Bortoletto ${ }^{3}$ \\ Marcio José de Almeida ${ }^{4}$ \\ Regina Melchior ${ }^{5}$ \\ Elisabete de Fátima Polo Almeida Nunes ${ }^{6}$
}

A intenção deste ensaio é a de refletir sobre algumas das possibilidades de uso da fenomenologia heideggeriana na análise de fenômenos ligados ao processo de ensino-aprendizagem na área da saúde. Este ensaio, primeiramente, abordará o surgimento da fenomenologia e aspectos comuns e discrepantes relativos à fenomenologia de Husserl e à fenomenologia de Heidegger. Posteriormente, analisará algumas das contribuições de Heidegger sobre fenômenos relacionados às áreas da saúde e do ensino. Por fim, serão tecidas considerações sobre algumas das possibilidades de uso da fenomenologia heideggeriana na análise de fenômenos ligados à formação na área da saúde.

\section{Fenomenologia de Husserl e Fenomenologia de Heidegger}

A fenomenologia surgiu na Alemanha no final do século XIX e início do século XX. Seu grande idealizador foi Franz Brentano (1838-1917), entretanto, foi seu discípulo, Edmund Husserl, (1859-1938) que, sob influência de Platão e Descartes, desenvolveu a fenomenologia como método de análise. Posteriormente, influenciou diversos pensadores, tais como: Martin Heidegger, Alfred Schutz, Jean Paul Sartre, Maurice Merleau-Ponty (Silva, Lopes, Diniz, 2008).

Husserl se propôs a estabelecer uma base segura, porém liberta de pressupostos, para a elaboração de novos conhecimentos nas ciências. Tinha como princípio a necessidade de observar os fenômenos tais como os mesmos se mostram para quem os observa. Independente de ser realidade ou aparência, para Husserl, se o fenômeno se mostra enquanto dado, ele pode e deve ser analisado em busca da verdadeira realidade (Mcconnell-Henry, Chapman, Francis, 2009).

Segundo ele, os pesquisadores que se orientavam pela linha positivista confundiam o ver em geral com o ver meramente sensível e experimental. Não compreendiam que cada objeto sensível e individual possui uma essência. $O$ individual, enquanto real, acidental - ao sentido deste acidental corresponde precisamente uma essência que precisa ser captada diretamente (Mcconnell-Henry, Chapman, Francis, 2009).

Husserl propõe, em seu método, a descrição da essência. Seu processamento é um esclarecimento gradual, que progride em etapas mediante a intuição intelectual da essência. Esse método filosófico desvela a cotidianidade do mundo
"Elaborado com base em González (2012): pesquisa aprovada pelo Comitê de Ética da Universidade Estadual de Londrina. Os autores agradecem ao professor Dr. Eder Soares Santos, que ajudou na revisão do artigo e no aprofundamento necessário no campo da filosofia sem comprometimento do direcionamento fundamental no campo da saúde e da educação.

1,5,6 Departamento de Saúde Coletiva, Centro de Ciências da Saúde, Universidade Estadual de Londrina (UEL). Av. Robert Koch, 60, Vila Operária. Londrina, PR Brasil. 86.038-350. betoduran@uel.br ${ }^{2}$ Departamento de Enfermagem, Centro de Ciências da Saúde, UEL.

${ }^{3,4}$ Programa de PósGraduação em Saúde Coletiva, Centro de Ciências da Saúde, UEL. 
do ser onde a experiência vivida torna-se centro da análise. Neste caso, experiência é a forma original pela qual os sujeitos concretos vivenciam o seu mundo (Mcconnell-Henry, Chapman, Francis, 2009).

A direção dada por Husserl à fenomenologia foi a de 'ir às coisas mesmas' (zu dem Sache selbst). A descrição fenomenológica proposta então possibilitou evidenciar o fenômeno em si mesmo, que, com o 'olhar habitual', não era possível. Nessa abordagem, o pesquisador considera sua vivência em seu 'mundo da vida' (Lebenswelt), uma experiência que lhe é própria, permitindo-lhe questionar o fenômeno que deseja compreender (Silva, Lopes, Diniz, 2008).

Heidegger rompe, em parte, com os conceitos introduzidos por Husserl e assume que a experiência diz respeito ao modo de ser do homem no mundo e está, sempre, localizada no tempo e no espaço (Alves, 2006).

Para Heidegger, o fenômeno se mantém velado frente ao que se mostra. Ao mesmo tempo, mostrase diretamente, de modo a constituir o seu sentido para quem o vivencia. O que ocorre é a possibilidade de algo que pode tornar-se fenômeno encobrir-se a ponto de o ser chegar ao esquecimento. É a possibilidade do esquecimento por conta do velamento do fenômeno que se tornou objeto da fenomenologia, aproximando, em seu conteúdo, o que exige tornar-se fenômeno. A partir dos escritos de Heidegger, pode-se compreender que o fenômeno é o que se mostra e o como se mostra.

Heidegger diferencia 'mostrar-se' (zeigen) e 'manifestar-se'. Considera que 'manifestação' (Erscheinung) pode significar anunciar-se, mesmo que de forma velada. Assim, o fenômeno não é uma manifestação e a manifestação é dependente de um fenômeno. Nesse sentido, a fenomenologia heideggeriana proporciona uma compreensão, pois procura valorizar o ser na sua singularidade.

A valorização do ser passa a possuir rigor científico e se fundamenta nas características do existir. A fenomenologia se ocupa em explicar as estruturas em que a experiência se verifica, descrevendo-as em suas estruturas ontológicas universais (Wojnar, Swanson, 2007).

Como opção metodológica, sua escolha depende da interrogação do pesquisador e da inquietação fundamental do estudo. Trata-se de uma postura diante do mundo porque necessita de uma abertura do pesquisador para a compreensão da vivência a partir do relato do outro, companheiro do pesquisador em seu processo de descoberta (Boemer, 1994). É essa possibilidade de compreensão que impulsiona o investigador. Esse caminhar fenomenológico é uma opção por um estilo de trabalhar, de pensar, de agir, de discursar e de se posicionar diante dos homens (Rezende, 1990), do mundo e da história (Heidegger, 2007).

Os parágrafos anteriores apresentaram algumas características que constituem a Fenomenologia de Husserl e a de Heidegger. Resumidamente, Husserl buscou a construção epistemológica de um método de elaboração de conhecimentos com base na dualidade corpo/mente (Jardine, 1990), neutralidade do pesquisador (Paley, 2005) e rigor metodológico. Buscava pela descrição das coisas - 'Ir às coisas mesmas' (Gorner, 2002) -, a verdade por meio da 'redução fenomenológica'(Giorgi, 2008) (Epoché), afastando a influência do tempo, do espaço e do contexto, com foco na necessidade da mensuração e da visualização do positivismo cartesiano (Overgaard, 2003).

Por outro lado, Heidegger buscou a construção de conhecimentos numa filosofia com foco na compreensão da experiência vivida pelo 'ser-aí' (Dasein) em seu existir no mundo para a interpretação e elaboração dos conhecimentos. Este 'ser-aí' é entendido como o ente que possui, em seu modo de ser, entre outras coisas, a possibilidade de questionar-se e de buscar o sentido de ser sendo no mundo (Heidegger, 2007). Heidegger não se dispôs a estabelecer um método, mas, sim, conhecimentos filosóficos que valorizem o contexto da experiência vivida no fenômeno, assim como os das experiências anteriores do próprio pesquisador. Tempo e espaço são fundamentais para a interpretação dos modos do 'ser-aí' (Heidegger, 2007).

\section{'Ser-com' como preocupação com o ser-enfermo}

Entende-se que o processo saúde-doença se mostra e se vela como fenômeno que exige o desvelamento de sentidos e de diferentes modos do 'ser-al'. Inúmeros estudos buscam a compreensão do sentido do 'ser-al' em situações de padecimento (Leiden) (Nogueira, 2011, 2008, 2006; Chang, Horrocks, 2006; Ayres, 2005, 2004, 2001; Caprara, 2003). 
Heidegger veio a se ocupar das questões da saúde e da enfermidade em fase tardia de sua vida. Suas contribuições à interpretação fenomenológica da saúde mantiveram características fragmentárias e marginais. Os Seminários de Zollikon, realizados a partir de 1959, para profissionais da área de saúde mental, formaram o principal corpo de análise sobre o tema, embora não se possa dizer que Heidegger tenha realizado um tratamento filosófico sistemático do assunto.

Os seminários de Zollikon significaram uma oportunidade para Heidegger abordar os padecimentos humanos em consonância com a analítica do 'ser-al' e seus fundamentos ontológicos. Heidegger explica didaticamente que há dois tipos de fenômenos: o ôntico (ontisch), que é perceptível, e o ontológico (Ontologisch), que não é perceptível, porém condição necessária para se compreenderem os fenômenos ônticos (Heidegger, 2009).

Desde a Grécia Antiga, a compreensão e o diagnóstico das enfermidades foram apoiados em algum tipo de ontologia. Mesmo hoje, quando um médico diz que uma pessoa apresenta uma dita enfermidade, está recorrendo à concepção metafísica cartesiana fundamentada na distinção entre objeto e sujeito e na exigência de mensuração com critérios ontológicos para identificar os fenômenos ônticos (Nogueira, 2011).

Para Nogueira (2007), existem três pressupostos teóricos importantes para a análise da dinâmica ôntica da saúde: a) a privação da potencialidade de ser no padecimento; b) o poupar do mundo em suas interpelações ou demandas no padecimento, e c) a necessidade constante de ajuda nessa condição privativa.

O conjunto destes três pressupostos indica que o padecimento é acompanhado sempre de uma restrição da liberdade do 'ser-al'. Esta limitação da possibilidade de viver é implicada pela desestruturação da cotidianidade do 'ser-a'. Isto não deve ser entendido como uma necessidade de sempre contar com apoio de profissionais. Inicialmente, refere-se à ajuda humana de convivência no mundo, na qual o 'ser-aí desde sempre se encontra, e só secundariamente diz respeito à ajuda profissional. O homem precisa de ajuda porque é sempre heterônomo em seu modo de 'ser-com' (Mitsein) os outros no mundo. O padecimento apenas torna mais ampla e diversificada essa necessidade de ajuda.

O enfoque fenomenológico compreende o humano enquanto 'ser-no-mundo' (in der Welt sein), na situação de 'estar-lançado' (Geworfenheit)na 'existência' (Existenz), sendo presente e presença. Possibilita-nos, portanto, a compreensão do ser enquanto ser existencial, valorizando-o e permitindo-o ser presença no lidar com o outro, considerando-o em sua vivência, a seu modo, o 'ser si-mesmo' (Selbstein) (Silva, Lopes, Diniz, 2008). Assim, aproximamo-nos do 'ser-al' com sua liberdade restrita ou não.

Heidegger (2007), analisando a fábula intitulada Cura, relaciona o cuidado com a 'existência'do homem. Relata que esta condição está também fundamentada na concepção de homem constituído de corpo e alma unos. Sendo assim, o "ente humano" possui sua origem no cuidado (Sorge), de tal modo que, enquanto ele "for e estiver no mundo", é mantido e está no cuidado, Assim, o cuidar é inerente ao homem. É uma das características do ser do homem. Heidegger argumenta que é impossível pensar o cuidado sem a 'temporalidade' (Zeitlichkeit), como se ambos formassem uma unidade. O cuidado, desta forma, recebe sua origem na temporalidade, e é o que the possibilita apreender o ser no mundo como totalidade: lançado, decaído e se projetando para o futuro (Michelazzo, 1999).

Heidegger descreve duas possibilidades de expressão do cuidado, de preocupação (Fürsorge). A primeira diz respeito à preocupação substitutiva, fazer pelo outro (einspringen). Dessa forma, pode retirar o cuidado do outro e tomar-Ihe o lugar nas ocupações, substituindo-o. Essa forma de cuidar assume a ocupação que o outro deve realizar e este é deslocado de sua posição, retraindo-se, para, posteriormente, assumir a ocupação como algo disponível e já pronto, ou então se dispensar totalmente dela. Nessa forma de cuidado, o outro pode tornar-se dependente e dominado, mesmo que esse domínio seja silencioso e permaneça encoberto para o dominado. Essa preocupação substitutiva retira do outro o cuidado, determina a convivência recíproca em larga escala e, na maior parte das vezes, diz respeito à ocupação manual, automatizada e alienada (Heidegger, 2007).

A segunda possibilidade de expressão do cuidado trata de favorecer o outro em suas potencialidades para vir a ser, ajudando-o a cuidar de si próprio, preocupação libertadora (vorauspringen). Ocorre um 
movimento de antepor-se ao outro em sua possibilidade existencial de ser, não para lhe retirar o cuidado, mas, sim, para devolvê-lo como tal. Essa forma diz respeito à cura propriamente dita, ou seja, à existência do outro, e não a uma coisa de que se ocupa. É uma maneira de ajudar o outro a tornar-se, cuidar-se, transparente a si mesmo e livre (Heidegger, 2007).

Na preocupação libertadora, o profissional pode ora precipitar-se por sobre o outro, fazer tudo por ele, mimá-lo, manipulá-lo, ainda que de forma sutil, e, em outros momentos, criar espaços para que o outro seja capaz de assumir seus próprios caminhos, ainda que com o amparo desse alguém que lhe é solícito.

Em síntese, o profissional pode tomar a condição de padecimento do outro como uma maneira de estar no mundo temporária ou definitiva, fazendo de sua prática uma ação de cuidado próprio com o outro, ajudando-o a resgatar sua liberdade; ou impróprio, restringindo-o ainda mais em suas possibilidades de liberdade. Espera-se do profissional de saúde ajuda, e não uma ação limitante e alienada no padecimento.

Estas reflexões conduzem a propostas profundas que trazem para o centro da discussão a formação para o cuidado. Portanto, isso também traz grandes desafios práticos, tanto para os profissionais de saúde ligados ao mundo do trabalho quanto aos ligados ao mundo da formação em saúde.

A atitude de cuidar não pode ser apenas uma pequena e subordinada tarefa parcelar das práticas de saúde. Envolve desafios éticos, morais e políticos advindos do apoio de instituições e culturas da saúde na racionalidade e autoridade científico-tecnológicas que dominam as ações de atenção à saúde propriamente dita (Ayres, 2001). Podemos acrescentar as influências que esses mesmos desafios provocam no campo da formação em saúde.

No padecimento, a disponibilidade desse profissional para abrir-se, compreender e lidar com o outro que se encontra nessa situação precisa ser despertada e desenvolvida, uma vez que, para isso, ele se coloca diante da existência do outro e da sua própria. Na perspectiva ontológica de Heidegger, o profissional de saúde tem o seu 'ser-al' envolvido com o "ser-que-está-doente", e a partir do momento que assume o cuidado do paciente, passa a "ser-com-o-outro", e essa relação sempre afeta, de alguma maneira, a sua existência.

\section{A docência e a formação na área da saúde}

Os conceitos educacionais trabalhados neste ensaio se baseiam na fenomenologia heideggeriana. A principal preocupação de Heidegger foi com o pensamento (Denken). Mencionou em seus escritos que é mais relevante pensar alguma coisa do que pensar sobre alguma coisa. Desta forma, propõe que, quando se quer procurar 'pensar alguma coisa', se procure entender o ser mesmo dessa coisa (Heidegger, 2008).

Refletirmos sobre a educação no caminho fenomenológico heideggeriano é nos preocuparmos com a educação mesmo, e não apenas com as técnicas de ensino-aprendizagem (Donnelly, 1999).

A educação embasada no existencialismo concentra sua atenção no estudante. Neste caso, a educação é entendida como um processo indireto em que o professor assume o papel de mediador. Os conhecimentos produzidos permitem o desenvolvimento de uma compreensão do indivíduo e de sua condição enquanto existência (Kahlmeyer-Mertens, 2008).

Para Heidegger, a maneira de pensar o ser se faz pela linguagem, pois o ser se comunica e se pronuncia pela linguagem. Coloca que a linguagem (Sprache) é a habitação do 'ser-al' (Heidegger, 2008). Este desafio exige um libertar-se, o que apresenta um caminho a ser trilhado com suas próprias possibilidades (Dall'alba, 2009; Peters, 2009). Assim, com base nos conceitos de Heidegger, pode-se indagar: o que cabe ao educador da área da saúde, frente a uma concepção de ensino e aprendizado que valorize a linguagem para além da oralidade como local privilegiado para ouvir o ser-docente?

$\mathrm{Na}$ educação, a relação "homem-sendo-com-outros-homens" se dá de forma peculiar, permitindo, com isso, a oportunidade da educação. A relação "homem-sendo-com-outros-homens" deixa, em muitos casos, de ser foco de atenção por suas características de obviedade e de pronta percepção (Heidegger, 2007). Por mais óbvio e evidente que seja 'ser-com', o outro abre a possibilidade de compreensão do sentido de ser em suas diferentes nuances. 
A compartimentação da educação por meio de diferentes adjetivos (educação religiosa, educação técnica, entre outras) fez com que se velasse a essência da própria educação (Critelli, 1981). Prioriza-se o ôntico pela especial atenção dada ao agir, limitando a educação à sua dimensão de instruir, em detrimento da tarefa ontológica da educação (Peters, 2003; Critelli, 2002). Esta afirmação rompe com a falsa ideia de que, em educação, necessitamos de mais ação e menos pensar. Assim ocorre em nossa contemporaneidade. A relação homem-homem deixou de ser "oportunidade" tornando-se "insumo" para a concretização da instrução, em geral técnica e destituída da busca de sentido (Leão, 2002).

Neste 'mundo-circundante' (Umwelt), mundo mais próximo do 'ser-al' no cotidiano, na espacialidade, o 'ser-al' que dele participa não se apropria do seu 'si-mesmo' (Selbst) próprio. Com isso passa a se relacionar de modo impróprio (Uneigentlich), o modo de "todos" e de "ninguém" (Heidegger, 1981). O existir de modo próprio ou de modo impróprio não é uma estrutura de valor ou de veracidade, mas sim uma constituição ontológica fundamental, portanto, o modo impróprio não é algo a ser superado. Deve ser entendido como modo constitutivo do existir cotidiano deste ente (Heidegger, 2007). Os homens impróprios formam e são derivados, em sua temporalidade, do mundo-circundante impróprio (Halliday, 1998).

Espaços educacionais que são dirigidos a "todos" são, sempre, endereçados a "ninguém", portanto, impessoais (Man). É a partir dessa conclusão que se pode perceber a possibilidade de pensarmos a educação como relação entre homem-homem com priorização da necessidade de compreensão de como é o 'ser-al' (Brook, 2009).

Caso a educação apenas abrisse caminhos para o impessoal, seria reduzida exclusivamente à sua dimensão ôntica. Como dito anteriormente, a educação se dá na relação "homem-sendo-com-outroshomens", possibilitando modos próprios e impróprios de ser frente ao modo de se relacionar, a preocupação (Critelli, 1981).

É, portanto, a partir da preocupação que devemos refletir os fenômenos da educação. A preocupação se dá pelo 'ser-no-mundo' com influência da temporalidade. No caso da educação, assim como na saúde, essa relação pode se concretizar como um modo dominador, preocupação substitutiva, ou como um modo libertador, preocupação libertadora.

A preocupação substitutiva, majoritariamente presente no cotidiano da educação, consiste em um 'saltar sobre o outro' (einspringen), aliviando-o e afastando a possibilidade de responsabilização pelo seu próprio ser (Peterson, 2005). Em contrapartida, a preocupação libertadora - 'saltar diante do outro' (vorauspringen) - entregando-o à sua própria facticidade (Fakticität), responsabilidade para ser livre para si (Gibbs, Angelides, Michaelides, 2004), permite que o outro se reconheça e se destine (Critelli, 1981).

Assim, pensar no papel do educador em saúde remete-nos à reflexão de que este deve significar ir além do instruir, treinar, supervisionar, para dar direção, conduzir, estar junto do estudante para ajudá-lo a abrir o caminho. Nesse caminho, o seu ato de conduzir permite ao estudante a possibilidade de descobrir, criar e construir.

Muitas vezes, o conhecimento é usado em sua ocupação, em sua 'manualidade' (Zuhandenheit) distorcida de vinculação docente-estudante. Esse tipo de vínculo pode causador sofrimento para o docente que exige de si ser detentor de todo o saber.

O docente que estuda para exclusivamente responder aos estudantes pode se perder da sua 'ocupação' (Besorgen) docente. Perde-se o sentido indagador e assume-se o papel de aquietador do pensamento do estudante e dele próprio. Acaba restringindo as possibilidades do estudante de projetarse. Limita, também, a si próprio por não se permitir na relação conjunta de construção de conhecimentos.

Heidegger (1954) aponta-nos um caminho para o ato de educar. Revela-nos que todo educador, todo filósofo, ensina porque está na alegria e na dor da aprendizagem, pois ensinar é o difícil método de quem deseja também aprender. Heidegger destaca a maior dificuldade de ensinar se comparada com aprender porque ensinar é deixar aprender.

Para ele, o estudante tem maior clareza de seu papel principal, o de aprender, enquanto o professor/ educador pode perder-se em sua função majoritária, pois o professor/educador deveria ser mais aberto à aprendizagem do que os próprios estudantes. Assim, no verdadeiro relacionamento do educador que, principalmente, ensina e dos estudantes que, principalmente, aprendem, não entra em cena o domínio. 
Leão (2002) refere que sendo o aprender um tomar posse que conduz a nossa identidade, é por esse aprender que responde o ensinar. Ensinar é um dar e prestar. O que no ensino se dá e se presta não são conteúdos técnicos, doutrinas, ou seja, apenas informações. São condições e indicações para se tomar e aprender por si mesmo o que já se tem. Por isso, se alguém aprende e toma apenas conteúdos e doutrinas, técnicas, armazenam-se apenas informações, não se aprende. Pois aprender não é acumular. Acontece realmente um aprender quando a compreensão do que se tem for e vier a ser sempre um dar-se a si mesmo na sua própria identidade. Nesse movimento, ensinar passa de simples informação e explicação para vir a ser formação e criação.

Heidegger diz que os pensadores e os poetas são os guardiões do ser que se desvela e vela na linguagem (Heidegger, 2008). Assim, para se alcançar uma linguagem própria e original da formação em saúde, é preciso oportunizar, aos estudantes, a possibilidade do pensar por 'si-mesmo'.

A prática educativa desenvolvida na área da saúde deve ser refletida quanto aos métodos de ensino e aprendizagem. Isto tem sido bastante debatido nas últimas décadas, e as ideias de Heidegger possibilitam uma reflexão acerca dessa prática.

Fernandes (2010) refere que debates na direção da humanização e do cuidado em saúde, discutindo a formação, tem sido uma preocupação constante no ambiente acadêmico. Debates que reconheçam a importância do caráter epistemológico do trabalho coletivo dos docentes em seus campos específicos do saber na área da educação e da saúde; inclusive, em sua competência política.

Assim, nessa conjuntura, os professores trabalham com a interface entre os limites e os desafios, e, consequentemente, também encontram novos desafios ao se depararem com novos limites que se originam no mundo dos valores. $\mathrm{O}$ ato de educar se fundamenta nesse mesmo mundo. O professor e o estudante se veem em situações geradas no processo de ensinar e aprender que não se separam do 'vir-a-ser'e do 'voltar-a-si-mesmo', ao olharem para realidades que podem ser transformadas. Nessa trajetória, constroem juntos uma história ao se indagarem como estão e como têm manifestado suas percepções e valores, bem como suas angústias e alegrias (Fernandes, 2010).

Ensinar e aprender, quando tomados existencialmente, não se restringem: à construção de projetos pedagógicos, planejamento de aulas, elaboração de instrumentos de avaliação, desenvolvimento de técnicas de ensino e de estudo, debates, trabalho em grupo, seminários, pesquisas, relatórios, estudos de casos etc., mas vão bem além. A busca constante do sentido de ser docente e ser estudante, durante a formação, é que oportunizará o caráter existencial da educação (Garanhani, Valle, 2010).

Para questionarmos verdadeiramente a formação, precisamos colocar a nós mesmos também em questão. Precisamos procurar um caminho e um jeito de caminharmos para formar e informar. Um caminho assim é o caminho de aprender e ensinar.

Confiar ao outro seu destino e a possibilidade de responsabilização por si é o principal desafio do professor. Para Critelli (1981), esta dificuldade ocorre porque escapa ao educador a possibilidade da determinação. Em uma reflexão mais profunda, essa possibilidade de determinação, se alguma vez existiu, era frágil e pouco precisa.

Os fenômenos da educação em saúde tendem à complexização quando se busca a compreensão, em um mesmo espaço e em um mesmo tempo, de fenômenos da educação e da saúde.

Este ensaio possibilita uma compreensão provisória de alguns elementos fundamentais para onde os conhecimentos da fenomenologia heideggeriana podem nos levar quando buscamos compreender fenômenos na formação em saúde. Abre-se, com isto, a possibilidade para que cada um possa trilhar seu próprio caminho por meio de eixos comuns. Assim, cada caminho poderá propiciar significado individual próprio da experiência vivenciada. 


\section{Colaboradores}

Alberto Durán González e Mara Lúcia Garanhani trabalharam na concepção, delineamento e redação deste artigo. Maira Sayuri Sakai Bortoletto, Marcio José de Almeida, Regina Melchior e Elisabete de Fátima Polo Almeida Nunes ajudaram no delineamento e na revisão crítica do manuscrito.

\section{Referências}

ALVES, P.C. A fenomenologia e as abordagens sistêmicas nos estudos sócio-antropológicos da doença: breve revisão crítica. Cad. Saude Publica, v.22, n.8, p.1547-54, 2006.

AYRES, J.R.C.M. Hermenêutica e humanização das práticas de saúde. Cien. Saude Colet., v.10, n.3, p.549-60, 2005.

O cuidado, os modos de ser (do) humano e as práticas de saúde. Saude Soc., v.13, n.3, p.16-29, 2004.

Sujeito, intersubjetividade e práticas de saúde. Cien. Saude Colet., v.6, n.1, p.63-72, 2001

BOEMER, M.R. A condução de estudos segundo a metodologia de investigação fenomenológica. Rev. Latin-am. Enferm., v.2, n.1, p.83-94, 1994.

BROOK, A. The potentiality of authenticity in becoming a teacher. Educ. Philos. Theory, v.41, n.1, p.46-59, 2009.

CAPRARA, A. Uma abordagem hermenêutica da relação saúde-doença. Cad. Saude Publica, v.19, n.4, p.923-31, 2003.

CHANG, K.H.; HORROCKS, S. Lived experiences of family caregivers of mentally ill relatives. J. Adv. Nurs., v.53, n.4, p.435-43, 2006.

CRITELLI, D.M. Martin Heidegger e a essência da técnica. Margem, v.1, n.16, p.83-9, 2002.

Para recuperar a educação (Uma aproximação à ontologia heideggeriana. In: (Ed.). Todos nós... ninguém: um enfoque fenomenológico do social. São Paulo: Moraes, 1981. p.59-72.

DALL'ALBA, G. Phenomenology and education: an introduction. Educ. Philos. Theory, v.41, n.1, p.7-9, 2009.

DONNELLY, J.F. Schooling Heidegger: on being in teaching. Teach. Teach. Educ., v.15, n.8, p.933-49, 1999.

FERNANDES, M.F.P. Prefácio. In: GARANHANI, M.L.; VALLE, E.R.M. (Eds.). Educação em enfermagem: análise existencial em um currículo integrado sob o olhar de Heidegger. Londrina: EDUEL, 2010. p.XI-XIV.

GARANHANI, M.L.; VALLE, E.R.M. Educação em enfermagem: análise existencial em um currículo integrado sob o olhar de Heidegger. Londrina: EDUEL, 2010.

GIBBS, P.; ANGELIDES, P.; MICHAELIDES, P. Preliminary thoughts on a praxis of higher education teaching. Teach Higher Educ., v.9, n.2, p.183-94, 2004.

GIORGI, A. Sobre o método fenomenológico utilizado como modo de pesquisa qualitativa nas ciências humanas: teoria, prática e avaliação. In: POUPART, J. et al. (Eds.). A pesquisa qualitativa: enfoques epistemológicos e metodológicos. Petrópolis: Vozes, 2008. p.386-409. (Coleção Sociologia).

GONZÁLEZ, A.D. Ser docente na área da saúde: uma abordagem à luz da fenomenologia heideggeriana. 2012. Tese (Doutorado em Saúde Coletiva) Universidade Estadual de Londrina, Londrina. 2012. 
GORNER, P. Heidegger's Phenomenology as transcendental philosophy. Int. J. Philos. Stud., v.10, n.1, p.17-33, 2002.

HALLIDAY, J. Technicism, reflective practice and authenticity in teacher education.

Teach. Teach. Educ., v.14, n.6, p.597-605, 1998.

HEIDEGGER, M. Seminário de Zollikon. Petrópolis: Vozes, 2009.

Construir, habitar, pensar. In: (Ed.). Ensaios e conferências. 5.ed. Petrópolis: Vozes, 2008. p.125-41.

Ser e tempo. 2.ed. Petrópolis: Vozes, 2007.

Todos nós... ninguém: um enfoque fenomenológico do social. São Paulo: Moraes, 1981.

Que'appelle-t-on penser? Paris: Quadrige P.U.F., 1954.

JARDINE, D.W. Awakening from Descartes' nightmare: on the love of ambiguity in phenomenological approaches to education. Stud. Philos. Educ., v.10, n.3, p.211-32, 1990.

KAHLMEYER-MERTENS, R.S. Heidegger e educação. Belo Horizonte: Autêntica Editora, 2008.

LEÃO, E.C. Aprendendo a pensar. 5.ed. Petrópolis: Vozes, 2002.

MCCONNELL-HENRY, T.; CHAPMAN, Y.; FRANCIS, K. Husserl and Heidegger:

exploring the disparity. Int. J. Nurs. Pract., v.15, n.1, p.7-15, 2009.

MICHELAZZO, J.C. Do um como princípio ao dois como unidade: Heidegger e a reconstrução ontológica do real. São Paulo: Fapesp/Annablume, 1999.

NOGUEIRA, R.P. Extensão fenomenológica dos conceitos de saúde e enfermidade em Heidegger. Cien. Saude Colet., v.16, n.1, p.259-66, 2011.

Estresse e padecimento: uma interpretação de acordo com Heidegger.

Interface - Comunic., Saude, Educ., v.12, n.25, p.283-93, 2008.

A saúde da Physis e a saúde do Dasein em Heidegger. Physis, v.17, n.3, p.429-50, 2007.

Para uma análise existencial da saúde. Interface - Comunic., Saude, Educ. v.10, n.20, p.333-45, 2006.

OVERGAARD, S. Heidegger's early critique of Husserl. Int. J. Philos. Stud., v.11, n.2, p.157-75, 2003.

PALEY, J. Phenomenology as rhetoric. Nurs. Inq., v.12, n.2, p.106-16, 2005.

PETERS, M.A. Technologising pedagogy: the internet, nihilism, and phenomenology of learning. Simile, v.3, n.1, p.1-10, 2003.

Editorial: Heidegger, Phenomenology, Education. Educ. Philos. Theory, v.41, n.1, p.1-6, 2009

PETERSON, T.E. Notes on Heidegger's authoritarian pedagogy. Educ. Philos. Theory, v.37, n.4, p.599-623, 2005.

REZENDE, A.M. Concepção fenomenológica da educação. São Paulo: Cortez, 1990.

SILVA, J.M.D.O.E.; LOPES, R.L.M.; DINIZ, N.M.F. Fenomenologia. Rev. Bras. Enferm., v.61, n.2, p.254-7, 2008.

WOJNAR, D.M.; SWANSON, K.M. Phenomenology: an exploration. J. Holist. Nurs., v.25, n.3, p.172-85, 2007. 
Reflete-se sobre as possibilidades da fenomenologia heideggeriana como referência na análise da educação na saúde. Heidegger propõe, em "Ser e tempo", a investigação sobre o sentido do ser, fundamental para o conhecimento que o homem possa ter de si mesmo como ser finito. Suas ideias provocaram transformações na concepção humanista moderna e na prática em educação. O indivíduo é sempre ator, sendo na medida em que existe, experimentando a si próprio na existência. O modo de ser privativo da saúde, o padecimento, é acompanhado sempre de uma limitação da possibilidade de viver. Assim, a fenomenologia heideggeriana nos ajuda a questionar a educação em saúde. Compreende-se que o homem se encontra sempre em copresença, entre a preocupação substitutiva e a libertadora. Este caminho se mostra possível quando contemplados os diversos modos de ser-professor e de ser-estudante. Possibilita-se, assim, aprofundar o ensinar-aprender na formação em saúde.

Palavras-chave: Metodologia. Educação. Processo saúde-doença. Fenomenologia. Heidegger.

\section{Heidegger's phenomenology as a framework for health education studies}

This essay reflects on the possibilities of Heidegger's phenomenology as a reference in the analysis of health education. In "Being and Time", Heidegger advocates the investigation of the meaning of the being, which is crucial for man's understanding of himself as a mortal being. Heidegger's ideas have caused transformations in the modern humanist conception and in education practice. The individual is always an actor as he/she exists, experimenting with him/herself within existence. The way of being that deprives of health, suffering, always comes along with a limitation of the possibility of living. Thus, Heidegger's phenomenology helps us question health education. We understand that man is always in co-presence, between substitutive preoccupation and liberating preoccupation. This path proves to be possible when different ways of being-professor and being-student are considered. Therefore, Heidegger's thought enables to deepen the teaching-learning that takes place in health education.

Keywords: Methodology. Education. Health-disease process. Phenomenology. Heidegger.

\section{La fenomenologia de Heidegger como referencia para estudios de formación en salud}

Se reflexiona sobre las posibilidades de la fenomenología de Heidegger para análisis de la educación en salud. Heidegger propone en "Ser y Tiempo" la investigación sobre el sentido del ser, fundamental para el conocimiento de que el hombre puede tener de sí mismo como un ser finito. Sus pensamientos causaron transformaciones en la concepción moderna humanista y la práctica educativa. El indivíduo es siempre actor em la medida em que existe, experimentando a si mismo en la existencia. La enfermedad siempre va acompañada de una limitación de la posibilidad de vivir. La fenomenología de Heidegger nos ayuda a cuestionar la educación en salud. Se entiende que el hombre está siempre en co-presencia, entre la preocupación substitut y la libertadora. Esta ruta se muestra posible al contemplar las diversas formas de serprofesor y ser-estudiante. Permite mejorar la enseñanza-aprendizaje en la formación en salud.

Palabras clave: Metodología. Educación. Proceso salud-enfermedad. Fenomenología. Heidegger. 
